\title{
RALA complexed $\alpha$-TCP nanoparticle delivery to mesenchymal stem cells induces bone formation in tissue engineered constructs in vitro and in vivo
}

Binulal N. Sathy ${ }^{1}$, Dinorath Olvera ${ }^{1}$, Tomas Gonzalez-Fernandez ${ }^{1}$, Gráinne M. Cunniffe ${ }^{1}$, Sreekanth Pentlavalli ${ }^{5}$, Philip Chambers ${ }^{5}$, Oju Jeon ${ }^{7}$, Eben Alsberg ${ }^{7,8,9}$, Helen O. McCarthy ${ }^{5}$, Nicholas Dunne ${ }^{5,6}$, Tammy L. Haut Donahue ${ }^{10,11}$, *Daniel J. Kelly ${ }^{1,2,3,4}$.

${ }^{1}$ Trinity Centre for Bioengineering, Trinity Biomedical Sciences Institute, Trinity College Dublin, Dublin, Ireland.

${ }^{2}$ Department of Mechanical and Manufacturing Engineering, School of Engineering, Trinity College Dublin, Dublin, Ireland.

${ }^{3}$ Department of Anatomy, Royal College of Surgeons in Ireland, Dublin, Ireland.

${ }^{4}$ Advanced Materials and Bioengineering Research Centre (AMBER), Royal College of Surgeons in Ireland and Trinity College Dublin, Dublin, Ireland.

${ }^{5}$ School of Pharmacy, Queen's University Belfast, 97 Lisburn Road, Belfast BT9 7BL, UK.

${ }^{6}$ School of Mechanical and Manufacturing Engineering, Dublin City University, Dublin, Ireland.

${ }^{7}$ Department of Biomedical Engineering, Case Western Reserve University, Cleveland, USA.

${ }^{8}$ Department of Orthopaedic Surgery, Case Western Reserve University, Cleveland, USA.

${ }^{9}$ National Centre for Regenerative Medicine, Case Western Reserve University, Cleveland, USA.

${ }^{10}$ School of Biomedical Engineering, Colorado State University, Fort Collins, CO, USA.

${ }^{11}$ Department of Mechanical Engineering, Colorado State University, 1374 Campus Delivery, Fort Collins, CO 80523, USA.

*Corresponding Author: Tel: +353-1-8963947, email: kellyd9@tcd.ie 


\section{Abstract}

A range of bone regeneration strategies, from growth factor delivery and/or mesenchymal stem cell (MSC) transplantation to endochondral tissue engineering, have been developed in recent years. Despite their tremendous promise, the clinical translation and future use of many of these strategies is being hampered by concerns such as off target effects associated with growth factor delivery. Therefore the overall objective of this study was to investigate the influence of alpha-tricalcium phosphate $(\alpha-\mathrm{TCP})$ nanoparticle delivery into MSCs using a RALA cell penetrating peptide on osteogenesis in vitro and both intramembranous and endochondral bone formation in vivo. RALA conjugated $\alpha$-TCP nanoparticle delivery to MSCs resulted in an increased expression of bone morphogenetic protein-2 (BMP-2) and an upregulation in a number of key osteogenic genes. When $\alpha$-TCP stimulated MSCs were encapsulated into alginate hydrogels, enhanced mineralization of the engineered construct was observed over a 28 day culture period. Furthermore, the in vivo bone forming potential of RALA conjugated $\alpha$-TCP nanoparticle delivery to MSCs was found to be comparable to growth factor delivery. Recognizing the potential and limitations associated with endochondral bone tissue engineering strategies, we then sought to explore how $\alpha$-TCP nanoparticle delivery to MSCs influences early mineralization of engineered cartilage templates in vitro and their subsequent ossification in vivo. Despite accelerating mineralization of engineered cartilage templates in vitro, RALA conjugated $\alpha$-TCP nanoparticle delivery did not enhance endochondral bone formation in vivo. Therefore the potential of RALA conjugated $\alpha$-TCP nanoparticle delivery appears to be as an alternative to growth factor delivery as a single stage strategy for promoting bone generation. 


\section{Introduction}

Bone tissue engineering approaches commonly use temporary matrices in the form of scaffolds and hydrogels loaded with growth factors and/or exogenous mesenchymal stem cells (MSCs) to enhance regeneration ${ }^{1-4}$. To date two distinct strategies have been employed to engineer functional bone using MSCs. The most commonly adopted approach is the direct conversion of MSCs in the engineered construct to bone forming cells, the deposition of bone specific matrix followed by its mineralization through simulating the process of intramembranous ossification. This is commonly implemented by employing hydrogels or scaffolds loaded or stimulated with growth factors that induce osteogenic differentiation of the incorporated or recruited MSCs ${ }^{5-8}$. An alternative approach is the engineering of a hypertrophic cartilaginous template by inducing chondrogenic lineage differentiation in bone marrow derived MSCs in order to recapitulate the developmental process of endochondral ossification ${ }^{9-11}$.

Several studies have convincingly demonstrated the potential of these approaches for functional bone regeneration, however a number of challenges remain. A well-documented concern relates to undesired side-effects associated with the supra-physiological delivery of growth factors in vivo ${ }^{12,13}$. Alternatively, when MSCs or engineered tissues are delivered to a site of bone injury, the immediate low-oxygen environment which is typical at the implantation site can negatively affect their survival rate ${ }^{14,15}$. Bone regeneration via an engineered cartilage template (endochondral tissue engineering) can theoretically addresses the challenges associated with growth factor delivery and the survival of cells as chondrocytes are better equipped to remain viable within such low-oxygen conditions. In addition, hypertrophic chondrocytes are known to produce pro-angiogenic factors which is advantageous for vascularization of the construct ${ }^{16-18}$. However, matrix mineralization using this approach largely depends on initiating a specific sequence of temporal molecular and cellular events starting from hypertrophy of chondrocytes, invasion of blood vessels, migration of osteoprogenitors and matrix mineralization ${ }^{16}$. The need for relatively longer in vitro culture periods for chondrogenic priming is also regarded as a hurdle that needs to be overcome to enable clinical translation of such approaches. Therefore investigating alternative strategies that facilitate control over stem cell lineage differentiation for functional bone formation (whether via intramembranous or endochondral pathways) is critical to developing more translational approaches to bone tissue engineering.

The use of osteoinductive biomaterials to control stem cell fate has been well documented in the literature ${ }^{19}$. Calcium phosphate $(\mathrm{CaP})$ based materials such as 
hydroxyapatite (HA) and $\alpha$ - or $\beta$-tricalcium phosphate ( $\alpha$-TCP, $\beta$-TCP) have been extensively investigated as scaffolding materials for bone regeneration and many of them are in clinical use $^{20-24}$. They are generally considered as osteoconductive and osteointegrative materials with good mechanical properties. However, recent literature has also demonstrated the osteoinductive properties of $\mathrm{CaP}$ based scaffolds in addition to their osteoconductive and osteointegrative properties ${ }^{19,24-27}$. Calcium ions and inorganic phosphate have been identified as key factors responsible for $\mathrm{CaP}$ based osteogenic differentiation and matrix mineralization ${ }^{28-30}$. Specifically, it has been demonstrated that bioactive factors such as BMP-2 are upregulated in stem cells in the presence of calcium ions ${ }^{29,31}$. Likewise, the role of CaP containing matrix vesicles in the mineralization of cartilage, bone and dentin has been clearly demonstrated in the literature ${ }^{32}$. Moreover their role as carries of growth factors is also well documented ${ }^{33,34}$.

Direct delivery of CaP nanoparticle into the cytosol of stem cells represents a promising approach for the controlled release of calcium and phosphate ions and the formation $\mathrm{CaP}$ containing matrix vesicles (MVs). Even though CaP nanoparticles have shown their potential to enter the cytosol through endocytosis, problems associated with agglomeration of bare $\mathrm{CaP}$ nanoparticles and the hydrophilic nature of the particles can be limiting factors associated with their intracellular delivery. Therefore, delivery of $\mathrm{CaP}$ nanoparticles using a vehicle that can effectively pass the cell membrane and into the cytosol could significantly improve the efficiency of this approach. Recently, a 30-amino acid cell penetrating amphipathic peptide RALA, made up of repeating arginine/alanine/leucine/alanine units ${ }^{35}$ has been shown to significantly improve the bioavailability of hydrophilic therapeutics ${ }^{36-38}$. The amphipathic RALA peptide interacts with the lipid-bilayers to transport cargo across cell membranes. The peptide can undergo endosomal disruption and escape due to the $\mathrm{pH}$ sensitive $\alpha$-helicity of the peptide to facilitate delivery of its cargo to the cytosol without degradation. Moreover, RALA mediated TCP nanoparticle delivery has been recently shown to enhance matrix mineralization of MSCs in 2D culture in comparison to bare TCP particles ${ }^{39}$. Based on these observations, we hypothesized that intracellular delivery of RALA conjugated $\alpha$-TCP nanoparticle can trigger $\mathrm{Ca}^{+}$mediated osteogenic differentiation of MSCs and mineralization of the ECM to promote bone formation in vivo. Therefore, the overall objective of the study was to investigate the effect of RALA conjugated $\alpha$-TCP nanoparticle delivery to MSCs embedded within alginate hydrogels on osteogenesis in vitro and bone formation in vivo. The therapeutic potential of $\alpha$-TCP delivery will be evaluated within two different contexts. This study will 
first evaluate RALA conjugated $\alpha$-TCP nanoparticle delivery to MSCs as an alternative to growth factor delivery for promoting bone formation in vivo. Secondly, recognizing the potential and limitations associated with endochondral bone tissue engineering strategies, this study will then explore if $\alpha$-TCP nanoparticle delivery to MSCs accelerates both mineralization of engineered cartilage templates in vitro and their subsequent ossification in vivo.

\section{Materials and methods}

\subsection{Experimental design}

This study was designed to investigate the osteogenic effect of delivering $\alpha$-TCP nanoparticles conjugated to a RALA delivery peptide (hereafter known as RTCP) to MSCs. MSCs were either encapsulated in empty or growth factor (GF) loaded cell adhesion motif arginyl-glycylaspartic acid (RGD) ${ }^{40}$ conjugated alginate hydrogels. Three systematic in vitro studies and two in vivo studies were performed. The composition of the hydrogels used in this study is summarized in Table 1. As part of in vitro study 1, osteogenic gene expression in MSCs following RALA mediated $\alpha$-TCP delivery (hereafter known as RTCP-MSC) was evaluated over a 2 week culture period in the absence of external osteogenic growth factors. As part of in vitro study 2 , the inherent bone forming potential of RTCP-MSCs was evaluated by encapsulating them in RGD-alginate hydrogels (hereafter known as RTCP-MSC-hydrogel). Constructs were cultured in the absence of osteogenic supplements and growth factors (GFs) for a period of 4 weeks. As part of in vitro study 3 , the effect of RALA mediated $\alpha$-TCP delivery to MSCs was evaluated in the presence of osteogenic and chondrogenic culture supplements. Untreated (control) MSCs (hereafter known as C-MSC) were encapsulated in RGD-alginate (hereafter known as C-MSC-hydrogel) as a control. For the in vivo studies, MSCs were encapsulated in RGD-alginate hydrogel loaded with the growth factors (BMP-2 and TGF $\beta-3$ ) which have previously been shown to promote bone formation following subcutaneous implantation into mice ${ }^{6}$ (hereafter known as $C$-MSC-GF-hydrogel). The synergistic effect of $R T C P$ and GF delivery was also investigated in this study by evaluating RTCP-MSCs encapsulated in these $G F$ delivery hydrogels (RTCP-MSC-GF-hydrogel). C-MSCs-hydrogels were used as controls. As part of in vivo study 1, bone formation following subcutaneous implantation of RTCP-MSCs-hydrogel and RTCP-MSC-GF-hydrogel was evaluated for a period of 8 weeks. Additionally, the synergistic effects of RTCP delivery and GF-delivery were evaluated. In the second in vivo study, the effect of 6 weeks of in vitro chondrogenic priming of RTCP-MSC-hydrogels and C-MSC-hydrogel on subsequent bone formation in vivo was 
assessed. Experimental groups, conditions and time course of experiments are summarized in Table 2.

\subsection{RTCP nanoparticle formulation}

The synthesis of $\alpha$-TCP and formulation of RTCP nanoparticles were carried out as we previously reported ${ }^{41}$ Briefly, $\alpha$-TCP $\left(\mathrm{Ca}_{3}(\mathrm{PO})_{4}\right)$ nanoparticles were prepared using dicalcium phosphate $\left(2 \mathrm{CaHPO}_{4}\right)$ and calcium carbonate $\left(\mathrm{CaCO}_{3}\right)$ precursors according to the solid state reaction given in Equation $1{ }^{42}$

$$
2 \mathrm{CaHPO}_{4}(\mathrm{~s})+\mathrm{CaCO}_{3}(\mathrm{~s}) \longrightarrow \mathrm{Ca}_{3}(\mathrm{PO})_{4}(\mathrm{~s})+\mathrm{CO}_{2}(\mathrm{~g})+\mathrm{H}_{2} \mathrm{O}(\mathrm{g}) \quad \text { Equation } 1
$$

Prepared nanoparticles were conjugated with RALA peptide by adding RALA (Biomatik, USA) and $\alpha$-TCP in a ratio of 5:1, in ultra-pure water. Nanoparticles were allowed to form by spontaneous electrostatic interactions between the cationic peptide and anionic $\mathrm{CaP}$ at room temperature for approximately $30 \mathrm{~min}$. Prepared $R T C P$ nanoparticles were stored at $4^{\circ} \mathrm{C}$ for a period of 2-4 weeks before usage.

\subsection{MSC culture and intracellular delivery of RTCP.}

Bone marrow derived porcine MSCs were isolated according to a modified method developed for human MSCs ${ }^{43}$, expanded and cryopreserved as previously described ${ }^{44}$. Cryopreserved MSCs were expanded in T-175 flasks (Thermo Fisher Scientific, Ireland) at a density of 5000 cells per $\mathrm{cm}^{2}$ in cell growth media (CGM) consisting of high glucose Dulbecco's modified eagle's medium GlutaMAX (hgDMEM), 10\% (v/v) foetal bovine serum (FBS), $100 \mathrm{U} \mathrm{mL}^{-1}$ penicillin - $100 \mu \mathrm{g} \mathrm{mL}^{-1}$ streptomycin (all from Gibco; Biosciences, Ireland) and $2.5 \mu \mathrm{g} \mathrm{mL}$ amphotericin B (Sigma-Aldrich, Ireland) Passage 2 MSCs were used for all studies. For intracellular delivery of RTCP nanoparticles, MSCs were plated at a density of $1 \times 10^{4}$ cells per $\mathrm{cm}^{2}$ in T-175 cell culture flasks and incubated for $24 \mathrm{~h}$ in cell growth media. Prior to RTCP treatment, CGM was removed from the flasks and MSCs were washed twice using OptiMEM without serum (Biosciences, Ireland). OptiMEM containing RTCP $\left(45.45 \mu \mathrm{g} \alpha-\mathrm{TCP} \mathrm{mL}^{-1}\right)$ was prepared immediately before delivery procedure and was added to the cell culture flask. Control MSCs were prepared by treating them with OptiMEM containing an equal volume of ultrapure water. MSCs were incubated with nanoparticles at $37{ }^{\circ} \mathrm{C}$ with $5 \% \mathrm{CO}_{2}$. At $6 \mathrm{~h}$ of incubation, media with $R T C P$ was removed and washed once with CGM and incubated with fresh CGM overnight at $37{ }^{\circ} \mathrm{C}$ with $5 \% \mathrm{CO}_{2}$. After overnight incubation, media was removed, washed 3 times with PBS and MSCs were trypsinized for further experiments. 


\subsection{Gene expression analysis}

$R T C P$ delivered MSCs and control MSCs were plated at a density of $5 \times 10^{5}$ cells per well in a 6-well plate and were incubated in cell neutral media (CNM) composed of hgDMEM supplemented with $3 \% \mathrm{FBS}, 100 \mathrm{U} \mathrm{mL}^{-1}$ penicillin- $100 \mu \mathrm{g} \mathrm{mL} \mathrm{L}^{-1}$ streptomycin and $2.5 \mu \mathrm{g} \mathrm{mL}$ ${ }^{1}$ amphotericin $\mathrm{B}$ for a period of 2 weeks at $37^{\circ} \mathrm{C}$ with $5 \% \mathrm{O}_{2}$. Cell lysate for RNA isolation was prepared at 7 and 14 days of culture by lysing cells ( $n=3$ wells/group/time point) using RLT lysis buffer (Qiagen, UK) supplemented with $10 \mu \mathrm{mL}^{-1} \beta$-mercaptoethanol (Sigma-Aldrich, Ireland) and stored at $-80^{\circ} \mathrm{C}$. At the time of isolation, lysates were thawed and homogenized using a QIAshredder column (Qiagen, UK) and total RNA was isolated and purified using the RNeasy mini kit (Qiagen, UK) using the manufacturer's suggested protocol. Purity and yield of RNA was quantified using a NanoDrop Spectrophotometer (Labtech International, Uckfield, UK). For cDNA preparation, 50 ng total RNA per sample were reverse transcribed into cDNA per $20 \mu \mathrm{L}$ of reaction volumes using a high capacity reverse transcription cDNA kit (Applied Biosystems, UK) as per manufacturer's instructions. Quantitative PCR was performed in an ABI 7500 sequence detection system (Applied Biosystems, UK) using SYBR select master mix (Applied Biosystems, UK) for evaluating the expression of Collagen type-1 (Col-1), Runt related transcription factor 2 (Runx-2), Bone morphogenetic protein 2 (BMP-2), Transforming growth factor beta 3 (TGF-B3), Alkaline phosphatase (ALPL), Osteocalcin (BGLAP) and Glyceraldehyde-3-phosphate dehydrogenase (GAPDH) genes. Porcine specific primer sequences KiCqStart ${ }^{\circledR}$ SYBR $®$ Green Primers; Sigma, Ireland) that were used for amplification of these genes are listed in Table 3. Comparative Threshold (cT) data were analysed using the $\Delta \Delta \mathrm{CT}$ method as described previously ${ }^{45}$ with GAPDH as the endogenous control. Relative expression of the genes is presented as fold changes relative to the control group.

\subsection{Preparation $R G D-\gamma$ alginate and encapsulation of MSCS}

Gamma-irradiated (5 Mrad) RGD modified alginate (hereafter known as RGD- $\gamma$-alginate) was prepared as previously reported ${ }^{46}$. Briefly, RGD peptides were covalently conjugated to $\gamma$ irradiated alginate using aqueous carbodiimide chemistry followed by purification and sterilization as previously described ${ }^{47,48}$. A $4 \%$ solution of RGD alginate was prepared in ultrapure water by stirring overnight in a $50 \mathrm{~mL}$ falcon tube aseptically. $R T C P-M S C$ and control MSCs were prepared as mentioned above (2.3) and were suspended at a cell density of $20 \times 10^{6} \mathrm{MSCs}_{\mathrm{mL}}^{-1}$ within RGD- $\gamma$-alginate (2\%). To cast cylindrical hydrogels $(5 \mathrm{~mm}$ diameter x $3 \mathrm{~mm}$ height) MSC-RGD- $\gamma$-alginate hydrogel solution was pipetted into sterile 
agarose (3\% final) molds with a final concentration $50 \mathrm{mM} \mathrm{C}_{\mathrm{a}} \mathrm{Cl}_{2}$ and allowed to crosslink for 30 min at $37^{\circ} \mathrm{C}$.

\subsection{In vitro culturing of tissue engineered hydrogels}

MSCs encapsulated hydrogels were cultured in osteogenic, chondrogenic or neutral conditions for various studies in vitro. For osteogenic conditions, the hydrogel-cell constructs were maintained in CGM supplemented with $100 \mathrm{nM}$ dexamethasone, $10 \mathrm{mM} \beta$-glycerol phosphate, and $0.05 \mathrm{mM}$ ascorbic acid (all from Sigma-Aldrich, Ireland) at 20\% $\mathrm{O}_{2}$ for 3 weeks. For chondrogenic conditions, tissue engineered hydrogels were maintained in CGM without FBS, supplemented with $100 \mu \mathrm{g} \mathrm{mL} \mathrm{m}^{-1}$ sodium pyruvate, $40 \mu \mathrm{g} \mathrm{mL}^{-1} \mathrm{~L}$-proline, $50 \mu \mathrm{g} \mathrm{mL}^{-1} \mathrm{~L}$-ascorbic acid-2-phosphate, $1.5 \mathrm{mg} \mathrm{mL}^{-1}$ bovine serum albumin, $1 \mathrm{X}$ insulin-transferrin-selenium, $100 \mathrm{nM}$ dexamethasone (all from Sigma-Aldrich, Ireland) and $10 \mathrm{ng} \mathrm{mL}^{-1}$ recombinant human TGF- $\beta 3$ (ProSpec-Tany TechnoGene Ltd., Israel) for 3- 6 weeks at 5\% $\mathrm{O}_{2}$. For evaluating the intrinsic capability of RTCP-MSCs to form bone, and to evaluate the bone formation potential of GF delivery hydrogel in vitro, the hydrogel-cell constructs were maintained in CNM prepared as mentioned above (2.5) for 4 weeks. In all culture conditions, media change was performed twice weekly.

\subsection{Cell viability assessment using live/dead staining}

Live/dead staining at predetermined time points were performed using LIVE/DEAD ${ }^{\mathrm{TM}}$ viability/cytotoxicity assay kit (Invitrogen, Bioscience, Ireland) to evaluate the viability of MSCs in RTCP-MSC-hydrogel compared to that of C-MSC-hydrogel. Briefly, hydrogels were washed in PBS, sliced into halves and were incubated in $2 \mu \mathrm{M}$ calcein $\mathrm{AM}$ and $4 \mu \mathrm{M}$ ethidium homodimer-1-containing phenol-free DMEM (Sigma-Aldrich, Ireland). After 1 hour incubation, hydrogel-cell constructs were washed again in PBS and viability of encapsulated MSCs were assessed using a scanning confocal microscope (Olympus FV-1000, UK) at an excitation and emission wavelengths of 515 and $615 \mathrm{~nm}$. Analysis was performed in FV10ASW 2.0 Viewer software.

\subsection{In vivo subcutaneous implantation}

All animal experiments were approved by the ethics committee of Trinity College Dublin and the Irish Medicines Board (IMB). Six different groups (Table 2) were subcutaneously implanted subcutaneously into the back of transgenic Balb/C nude mice (Harlan, UK) $(n=8)$ using a previously described surgical procedure ${ }^{49}$. For implantation, two subcutaneous pockets (one in the shoulder level and one in the hip level) were created per animal under ascetic 
conditions. Next, three hydrogel-cell constructs were implanted per pocket ( $n=6$ per mouse). All the constructs were harvested at 8 weeks of in vivo implantation. Bone formation was analysed based on the gross appearance, micro computed tomography $(\mu \mathrm{CT})$ scan, biochemical evaluation and histology.

\section{$2.9 \mu \mathrm{CT}$ analysis}

$\mu \mathrm{CT}$ scans were performed soon after implant retrieval. All samples were scanned with a high resolution $\mu \mathrm{CT}$ imaging system (Scanco Medical, Bassersdorf, Switzerland) at a resolution of $10 \mathrm{~mm}$, a voltage of $100 \mathrm{kV}$, and current of $100 \mathrm{~mA}$. Volumetric reconstructions and analysis of the acquired data were performed by NRecon and CT Analyzer software provided by SkyScan. A cylindrical volume centred over the defect covering the entire construct was selected as the volume of interest (VOI). A global threshold of 70-255 was used for analysing the constructs. Reconstructed 3D images generated from the scans were used to visualize mineral distribution throughout the constructs.

\subsection{Biochemical analysis for sulphated glycosaminoglycan (sGAG), collagen and calcium} content.

Hydrogel-cell constructs were digested with papain enzyme as previously reported ${ }^{50}$. Briefly, papain buffer extract (PBE) was prepared using $100 \mathrm{mM}$ sodium phosphate buffer containing $0.1 \mathrm{M}$ sodium acetate, $0.05 \mathrm{M}$ ethylenediaminetetra-acetic acid, pH 6.0 (all from SigmaAldrich, Ireland). Papain (125 $\mu \mathrm{g} \mathrm{mL}^{-1}$, Sigma-Aldrich, Ireland) was activated with $10 \mathrm{mM}$ cysteine hydrochloride immediately before usage. DNA content was quantified using Hoechst Bisbenzimide 33258 dye assay (Quant-iT ssDNA Assay Kit, Biosciences). sGAG levels in the samples were measured using dimethylmethylene blue dye-binding assay, $\mathrm{pH} 1.35$ (Blyscan, Biocolor Ltd., UK). For the collagen assay, papain digested samples were hydrolysed by treating with concentrated $\mathrm{HCl}(37 \%)$ and collagen content in the samples was quantified by measuring their hydroxyproline content using the Chloramine-T assay as previously described 51. Acid digested hydrogel samples were used for the calcium assay. Briefly, hydrogel-cell constructs were digested with $1 \mathrm{M} \mathrm{HCl}$ and calcium in the samples was measured using standard calcium assay kit (Sentinel Diagnostics, Italy). Collagen and sGAG content in the constructs were normalised with DNA content and the calcium amount was normalised with the wet weight of the samples.

\subsection{Histological evaluation of the constructs}


Hydrogel-cell constructs were fixed in 4\% paraformaldehyde (Sigma-Aldrich, Ireland) at the end of study periods, dehydrated and wax embedded in paraffin. Seven- $\mu$ m thick sections were sliced from the paraffin embedded samples using a microtome (Leica, Germany). Sections were stained with aldehyde fuchsin/alcian blue (AF/AB) for visualizing sGAG, standard picrosirius red (PSR) for evaluating the collagen deposition, and alizarin red for evaluating the calcium deposition as previously described ${ }^{9}$. Semi-quantitative analysis of the stained area was performed using ImageJ (National Institute of Health).

\subsection{Statistical analysis}

Statistical analyses were performed by GraphPad Prism software (v.6, GraphPad, USA). Quantitative findings are presented as mean \pm SEM. Student's t-test was used to compare differences between two experimental groups. Multifactor analysis of variance (ANOVA) was performed followed by Tukey's multiple comparison test to determine statistical significance when comparison was made using more than two groups. The difference between groups was considered statically significant at $\mathrm{p}<0.05$.

\section{Results}

3.1. RALA conjugated $\alpha$-TCP nanoparticle delivery results in upregulation of osteogenic genes in MSCs

Delivery of RTCP to MSCs in monolayer in vitro culture induced upregulation of osteogenic genes (Fig. 2). Growth factor related genes such as BMP-2 and TGF- $\beta 3$ showed significant upregulation in RTCP treated groups compared to controls at 1 week. The expression of these genes returned to levels similar to that of untreated controls after 2 weeks. The osteogenic transcription factor Runx-2 was found to be upregulated at week 2. The osteogenic marker genes collagen type 1 and osteocalcin were also found to be significantly upregulated after two weeks in RTCP treated MSCs compared to controls.

3.2 RALA conjugated $\alpha$-TCP nanoparticle delivery to MSCs encapsulated in alginate hydrogels accelerates mineralization in vitro

RTCP-MSC remained viable over 4 weeks in vitro following encapsulation in alginate hydrogels, demonstrating comparable levels of viability to $C$-MSC (all groups maintained in media containing 3\% serum with no other growth factors added to the media) (Fig.3 A). H\&E staining revealed similar levels of tissue deposition in both groups in CNM (Fig.3 B). However, more intense alizarin red staining was observed in the RTCP-MSC-hydrogels. In agreement 
with histological findings, biochemical quantification confirmed significant increases in calcium deposition in the RTCP-MSC-hydrogels in comparison to C-MSC-hydrogels (Fig.3C).

\subsection{RALA conjugated $\alpha$-TCP nanoparticle delivery to MSCs supports mineralization in both} chondrogenic and osteogenic conditions

RTCP-MSCs remained viable in alginate hydrogels incubated in both chondrogenic and osteogenic culture conditions (Fig.4). There was no difference between RTCP-MSC-hydrogels and $C$-MSC-hydrogels in terms of cell viability after 1 week in chondrogenic media or osteogenic media. Cells were found to be more aggregated in RTCP-MSC-hydrogels in comparison to C-MSC-hydrogels in chondrogenic culturing conditions (Fig.4 A). RTCP-MSChydrogels appeared to contain a higher number of viable cells compared to controls when maintained in osteogenic media (Fig.4 B). In agreement with this, the DNA content of RTCPMSC hydrogels was higher in osteogenic conditions (Fig.4C), while no significant differences in DNA content were observed in chondrogenic conditions (Fig.4D).

$R T C P-M S C$ maintained their capacity to undergo chondrogenic and osteogenic differentiation following encapsulation in alginate hydrogels (Fig.5). In the presence of chondrogenic differentiation factors, RTCP-MSC-hydrogels contained similar levels of sGAGs and collagen to C-MSC-hydrogels (Fig.5 A). Nodules of mineral were observed in RTCP-MSC-hydrogels maintained in chondrogenic conditions which were absent in C-MSC-hydrogels (Fig.5 A). In the presence of osteogenic differentiation factors, staining for sGAG accumulation was more intense in RTCP-MSC-hydrogels, with no apparent differences in collagen accumulation as evidenced by picrosirius red staining. Staining for mineralization was more peripheral in $C$ MSCs-hydrogels but more homogenous in RTCP-MSCs-hydrogels (Fig.5 B).

3.4 The in vivo bone forming potential of RALA conjugated $\alpha$-TCP nanoparticle delivery to MSCs is comparable to growth factor delivery

After 8 weeks in vivo, RTCP-MSC-hydrogels, C-MSC-GF-hydrogels and RTCP-MSC-GFhydrogels had all formed a mineralized, bone-like tissue, while little evidence of calcification was observed in C-MSC-hydrogels (Fig.6. A and C). This was confirmed by microCT scanning, which revealed no statistically significant difference in mineral volume between the RTCPMSC-hydrogel, C-MSC-GF-hydrogel and RTCP-MSC-GF-hydrogel groups. The RTCP-MSChydrogels contained significantly higher levels of mineral compared to the C-MSC-hydrogels (Fig.6 G). The combination of RTCP delivery and growth factor delivery in RGD-alginate hydrogel did not lead to a synergistic increase in mineral deposition. Histological analysis 
showed a similar pattern of results when compared to the $\mu$ CT findings. There was no evidence of bone-like tissue formation (haematoxylin/eosin staining) or mineralization (alizarin red staining) in C-MSC-hydrogels compared to the other three groups (Fig.6 B and D). There was no statistically significant difference in collagen content among any of the groups (Fig.6E). Bone volume (quantified from histological images) was significantly higher following either RTCP delivery or growth factor delivery (Fig.6 F).

3.5 Despite accelerating mineralization of engineering cartilage templates in vitro, RALA conjugated $\alpha$-TCP nanoparticle delivery does not enhance endochondral bone formation in vivo

RTCP-MSC-hydrogels and C-MSC-hydrogels constructs were cultured for 6 weeks in chondrogenic growth conditions in vitro to engineer a cartilage template. Histological analysis revealed similar levels of sGAGs and collagen in both groups (Fig.7 A), however RTCP-MSChydrogels contained higher levels of calcium (Fig.7A, B). Bone formation in all chondrogenically primed constructs showed similar levels of bone formation 8 weeks after subcutaneous implantation (Fig.7 C). There were no significant differences in collagen content and mineral volume between the groups (Fig.7 D).

\section{Discussion}

The goal of this study was to investigate the potential of RTCP delivery to MSCs as a promising translational approach to generate engineered bone tissue. $\alpha$-TCP nanoparticles conjugated to a RALA delivery peptide were prepared and delivered to MSCs prior to encapsulation into an RGD-modified alginate hydrogel. The results from this study support the hypothesis that delivering RTCP to MSCs accelerates mineralization in vitro and improves bone formation in vivo. Of note was the finding that the osteoinductive effect of RTCP delivery was similar to that of delivering a combination of growth factors (BMP-2 and TGF- $\beta 3$ ) that was previously shown optimal for promoting bone formation ${ }^{6}$. In addition, RTCP delivery showed its potential to facilitate enhanced mineralization of engineered cartilage templates for endochondral bone formation strategies. Taken together, the results from this study demonstrate that a combinatorial approach involving MSCs and RTCP delivery has the potential to be used as a single stage strategy for bone regeneration without the need for exogenous growth factors.

Conjugation of $\alpha$-TCP with a RALA peptide has previously been shown to improve the intracellular delivery of CaP nanoparticles ${ }^{39,41,52}$. Conjugation of the $\alpha$-TCP nanoparticles to the RALA peptide limits agglomeration, with the suspension being stable for a period of 4 weeks at $4-37^{\circ} \mathrm{C}{ }^{41}$. In addition, the presence of the cell penetrating peptide RALA acts to 
mitigate the hydrophilicity-associated negative effects linked to bare $\mathrm{CaP}$ nanoparticles ${ }^{28}$ in terms of their capability to enter the cell membrane. CaP based biomaterials, including $\alpha$ and $\beta$-TCP, hydroxyapatite (HA) and calcium sulphate, have been extensively used in orthopaedics as a bone substitute material ${ }^{26,53,54}$. Nanoparticles in a size range of 20-200 $\mathrm{nm}$ has been shown to be optimal for intracellular delivery, with bare $\mathrm{CaP}$ nanoparticles often undergoing significant levels of agglomeration leading to development of a much larger particle size over time ${ }^{55-58}$. Thus, currently CaP nanoparticles are largely used with modifications to increase their stability and to control their size in order to improve their capacity to cross the cell membrane ${ }^{57}$. Even though use of $\mathrm{CaP}$ based nanoparticles as carriers for intracellular delivery of nucleic acids has been explored for 40 years, the inherent osteogenic effect of calcium and phosphate ions released from such particles has not been considered in the majority of the studies. This is despite the fact that several studies have separately reported the osteoinductive properties of $\mathrm{CaP}$ based agglomerates and bulk scaffolding materials $26,27,59$.

RTCP delivery to MSCs lead to an upregulation of the master osteogenic transcription factor Runx-2 and other osteogenic genes (Fig. 3) which was preceded by an increase in BMP2 expression. The potential of $\mathrm{Ca} 2+$ ions as osteoinductive cues is well established ${ }^{29-31}$. For example, a three-fold upregulation of BMP-2 in human bone marrow derived MSCs has previously been reported in response to high extracellular $\mathrm{Ca}^{+}$concentration $^{29}$. Activation of protein kinase $\mathrm{K}$ (PKA) followed by Ras-MAP-kinase signalling pathway by $\mathrm{Ca}^{+}$ions which are internalized, possibly through type-L voltage-gated calcium channels, has been proposed as the possible mechanism of BMP-2 activation ${ }^{29}$. This confirms that BMP signalling is one of the key events in RTCP mediated osteogenesis in MSCs. In the case of intracellular delivery of $\mathrm{CaP}$ nanoparticles using RALA mediated delivery, $\mathrm{Ca} 2^{+}$ions can be readily available in the cytosol for activating PKA. A similar effect was observed after MSCs were encapsulated into alginate hydrogels, where $\alpha$-TCP nanoparticle delivery also lead to increases in construct mineralization in vitro.

In addition to enhancing osteogenesis of MSC in vitro, RTCP delivery to MSCs induced similar levels of bone formation in vivo to that of growth factor delivery from hydrogels. Incorporation of RGD to alginate has been previously shown to create attachment points to control phenotype, enhance cell-matrix interactions and promote differentiation into mature osteoblasts from mouse and human pre-osteoblasts ${ }^{60,61}$ and human MSCs ${ }^{62}$. In addition, delivery of BMP-2 from these low molecular weight hydrogels have been shown to robust bone regeneration in vivo ${ }^{6,63}$. BMP-2 is long established as having potent osteoinductive properties 
64, 65, however there are well documented adverse outcomes associated with their use ${ }^{66-68}$. A recent review on the complications associated with BMP-2 delivery identified unanswered questions related to optimal dosing, repeat exposures, carcinogenesis and long-term results ${ }^{12}$. The fact RTCP delivered to MSCs encapsulated within alginate hydrogels showed similar level of bone formation to that of growth factor delivery from hydrogels points to their use as an alternative to BMP-2 delivery for the repair of large bone defects. Further evaluation of these constructs in orthotopic defects is required to validate these proof-of-concept findings.

RTCP delivery to MSCs accelerated mineralization of the matrix within tissue engineered constructs maintained in non-specific culture conditions and those known to promote chondrogenesis and endochondral ossification. During bone formation, osteoblast produce bone specific extracellular matrix which is mineralized with HA nanocrystals ${ }^{69}$. The unique organization of mineralized collagen matrix provides structural integrity and mechanical strength to bone. The role of CaP-containing vesicles in the matrix mineralization has been previously established ${ }^{28,32-34,70}$. This suggested that the release of $\mathrm{Ca}^{2+}$ and $\mathrm{PO}_{4}^{3-}$ ions from RTCP nanoparticles in the cytosol of MSCs enhanced $\mathrm{Ca}^{2+}$ and $\mathrm{PO}_{4}^{3^{-}}$accumulation in the MVs, resulting in enhanced mineralization of the matrix. However, delivery of RTCPs does not seem to have interfered with the chondrogenic potential of MSCs. This is an important finding which can have important implications in endochondral bone regeneration strategies. For example, it might enable shortening of the in vitro priming time necessary to engineer hypertrophic cartilage templates suitable for bone regeneration. Of note is the finding that the mineral volume of bony tissues generated in vivo from engineered cartilage templates was noticeably higher than that generated by either growth factor delivery or $\alpha$-TCP nanoparticle delivery (compare Fig. 6 and Fig. 7). Furthermore, these cartilaginous templates were noticeably more vascularized than other groups, suggesting that both nanoparticle and growth factor delivery strategies can be further improved to enhance their osteoinductivity.

In conclusion, the results of this study clearly demonstrate the osteo-inductive potential of RTCP nanoparticle delivery to MSCs for bone tissue engineering. Their delivery to MSCs results in increased expression of osteogenic growth factors and transcription factors, accelerated mineralization and robust bone development in vivo. Achieving osteogenic differentiation without the use of exogenous growth factors is a new and exciting approach in bone tissue engineering. This study demonstrates the potential of $\mathrm{CaP}$ nanoparticle delivery to 
drive osteogenesis and hence act as such as alternative to traditional growth factor delivery approaches.

\section{Acknowledgements}

This work was supported by a tri-partite project funded by Science Foundation Ireland (SFI), Department of Employment and Learning- Northern Ireland (DEL-NI) and the National Science Foundation (NSF) through the US-Ireland R\&D Partnership Programme (USI 044, SFI-12/US/I2489), SFI 12/IA/1554 and European Research Council Starter grant (258463).

\section{References}

1. A. R. Amini, C. T. Laurencin and S. P. Nukavarapu, Crit Rev Biomed Eng, 2012, 40, 363-408.

2. J. Henkel, M. A. Woodruff, D. R. Epari, R. Steck, V. Glatt, I. C. Dickinson, P. F. Choong, M. A. Schuetz and D. W. Hutmacher, Bone Res, 2013, 1, 216-248.

3. R. Quarto and P. Giannoni, Methods Mol Biol, 2016, 1416, 21-33.

4. G. J. Meijer, J. D. de Bruijn, R. Koole and C. A. van Blitterswijk, PLoS Med, 2007, 4, e9.

5. T. N. Vo, F. K. Kasper and A. G. Mikos, Adv Drug Deliv Rev, 2012, 64, 1292-1309.

6. C. A. Simmons, E. Alsberg, S. Hsiong, W. J. Kim and D. J. Mooney, Bone, 2004, 35, 562-569.

7. E. Nyberg, C. Holmes, T. Witham and W. L. Grayson, Drug Deliv Transl Res, 2016, 6, 184-194.

8. S. Almubarak, H. Nethercott, M. Freeberg, C. Beaudon, A. Jha, W. Jackson, R. Marcucio, T. Miclau, K. Healy and C. Bahney, Bone, 2016, 83, 197-209.

9. G. M. Cunniffe, T. Vinardell, J. M. Murphy, E. M. Thompson, A. Matsiko, F. J. O'Brien and D. J. Kelly, Acta Biomaterialia, 2015, 23, 82-90.

10. E. M. Thompson, A. Matsiko, E. Farrell, D. J. Kelly and F. J. O'Brien, J Tissue Eng Regen Med, 2015, 9, 889-902.

11. E. M. Thompson, A. Matsiko, D. J. Kelly, J. P. Gleeson and F. J. O'Brien, Tissue Eng Part A, 2016, 22, 556-567.

12. C. A. Tannoury and H. S. An, Spine J, 2014, 14, 552-559.

13. J. N. Zara, R. K. Siu, X. Zhang, J. Shen, R. Ngo, M. Lee, W. Li, M. Chiang, J. Chung, J. Kwak, B. M. Wu, K. Ting and C. Soo, Tissue Eng Part A, 2011, 17, 1389-1399.

14. K. M. Peterson, A. Aly, A. Lerman, L. O. Lerman and M. Rodriguez-Porcel, Life Sci, 2011, 88, 65-73.

15. C. Lu, M. Rollins, H. Hou, H. M. Swartz, H. Hopf, T. Miclau and R. S. Marcucio, Iowa Orthop J, 2008, 28, 14-21.

16. E. J. Mackie, Y. A. Ahmed, L. Tatarczuch, K. S. Chen and M. Mirams, Int J Biochem Cell B, 2008, 40, 46-62.

17. J. Dai and A. B. M. Rabie, J Dent Res, 2007, 86, 937-950.

18. U. I. Chung, Endocr J, 2004, 51, 19-24.

19. A. M. Barradas, H. Yuan, C. A. van Blitterswijk and P. Habibovic, Eur Cell Mater, 2011, 21, 407-429; discussion 429.

20. Y. K. Gan, K. R. Dai, P. Zhang, T. T. Tang, Z. N. Zhu and J. X. Lu, Biomaterials, 2008, 29, 3973-3982.

21. S. R. Dutta, D. Passi, P. Singh and A. Bhuibhar, Ir J Med Sci, 2015, 184, 101-106. 
22. J. Z. Liu, L. Zhao, L. Ni, C. Y. Qiao, D. W. Li, H. C. Sun and Z. T. Zhang, Am J Transl Res, 2015, 7, 1588-1601.

23. M. S. Nickoli and W. K. Hsu, Global Spine J, 2014, 4, 211-216.

24. P. Wang, L. Zhao, J. Liu, M. D. Weir, X. Zhou and H. H. Xu, Bone Res, 2014, 2, 14017.

25. Y. R. Shih, Y. Hwang, A. Phadke, H. Kang, N. S. Hwang, E. J. Caro, S. Nguyen, M. Siu, E. A. Theodorakis, N. C. Gianneschi, K. S. Vecchio, S. Chien, O. K. Lee and S. Varghese, Proc Natl Acad Sci U S A, 2014, 111, 990-995.

26. I. Denry and L. T. Kuhn, Dent Mater, 2016, 32, 43-53.

27. P. Gao, H. Zhang, Y. Liu, B. Fan, X. Li, X. Xiao, P. Lan, M. Li, L. Geng, D. Liu, Y. Yuan, Q. Lian, J. Lu, Z. Guo and Z. Wang, Sci Rep, 2016, 6, 23367.

28. S. Boonrungsiman, E. Gentleman, R. Carzaniga, N. D. Evans, D. W. McComb, A. E. Porter and M. M. Stevens, Proc Natl Acad Sci U S A, 2012, 109, 14170-14175.

29. A. M. C. Barradas, H. A. M. Fernandes, N. Groen, Y. C. Chai, J. Schrooten, J. van de Peppel, J. P. T. M. van Leeuwen, C. A. van Blitterswijk and J. de Boer, Biomaterials, 2012, 33, 3205-3215.

30. Y. L. Chang, C. M. Stanford and J. C. Keller, J Biomed Mater Res, 2000, 52, 270-278.

31. F. Viti, M. Landini, A. Mezzelani, L. Petecchia, L. Milanesi and S. Scaglione, Plos One, 2016, 11.

32. E. E. Golub, Biochim Biophys Acta, 2009, 1790, 1592-1598.

33. N. N. Nahar, L. R. Missana, R. Garimella, S. E. Tague and H. C. Anderson, J Bone Miner Metab, 2008, 26, 514-519.

34. N. N. Nahar, L. R. Missana, R. Garimella, S. E. Tague and H. C. Anderson, J Bone Miner Res, 2005, 20, S321-S321.

35. H. O. McCarthy, J. McCaffrey, C. M. McCrudden, A. Zholobenko, A. A. Ali, J. W. McBride, A. S. Massey, S. Pentlavalli, K. H. Chen, G. Cole, S. P. Loughran, N. J. Dunne, R. F. Donnelly, V. L. Kett and T. Robson, Journal of Controlled Release, 2014, 189, 141-149.

36. R. Bennett, A. Yakkundi, H. D. McKeen, L. McClements, T. J. McKeogh, C. M. McCrudden, K. Arthur, T. Robson and H. O. McCarthy, Nanomedicine-Uk, 2015, 10, 2989-3001.

37. J. McCaffrey, C. M. McCrudden, A. A. Ali, A. S. Massey, J. W. McBride, M. T. C. McCrudden, E. M. Vicente-Perez, J. A. Coulter, T. Robson, R. F. Donnelly and H. O. McCarthy, Journal of Controlled Release, 2016, 226, 238-247.

38. A. S. Massey, S. Pentlavalli, R. Cunningham, C. M. McCrudden, E. M. McErlean, P. Redpath, A. A. Ali, S. Annett, J. W. McBride, J. McCaffrey, T. Robson, M. E. Migaud and H. O. McCarthy, Mol Pharmaceut, 2016, 13, 1217-1228.

39. P. C. M.O'Doherty, S Pentlavalli, M. J. Chalanqui, H.M. Pauly, B. N. Sathy, T. H. Donahue, D.J. Kelly, N. Dunne and H. O. McCarthy, Advanced Healthcare Materials ( Submitted), 2016.

40. S. E. D'Souza, M. H. Ginsberg and E. F. Plow, Trends Biochem Sci, 1991, 16, 246-250.

41. M O'Doherty, P Chambers, M Chalanqui, H O McCarthy, N Dunne., 27th European Conference on Biomaterials (ESB 2015) 2015.

42. V. Jack, F. J. Buchanan and N. I. Dunne, P I Mech Eng H, 2008, 222, 19-28.

43. D. P. Lennon and A. I. Caplan, Experimental Hematology, 2006, 34, 1604-1605.

44. E. J. Sheehy, C. T. Buckley and D. J. Kelly, Biochem Biophys Res Commun, 2012, 417, 305-310.

45. T. D. Schmittgen and K. J. Livak, Nat Protoc, 2008, 3, 1101-1108.

46. E. Alsberg, H. J. Kong, Y. Hirano, M. K. Smith, A. Albeiruti and D. J. Mooney, J Dent Res, 2003, 82, 903-908. 
47. O. Jeon, C. Powell, S. M. Ahmed and E. Alsberg, Tissue Eng Pt A, 2010, 16, 29152925.

48. A. C. Daly, G. M. Cunniffe, B. N. Sathy, O. Jeon, E. Alsberg and D. J. Kelly, Adv Healthc Mater, 2016, DOI: 10.1002/adhm.201600182.

49. T. Vinardell, E. J. Sheehy, C. T. Buckley and D. J. Kelly, Tissue Eng Pt A, 2012, 18, 1161-1170.

50. C. T. Buckley, T. Vinardell, S. D. Thorpe, M. G. Haugh, E. Jones, D. McGonagle and D. J. Kelly, Journal of Biomechanics, 2010, 43, 920-926.

51. N. Y. Ignat'eva, N. A. Danilov, S. V. Averkiev, M. V. Obrezkova, V. V. Lunin and E. N. Sobol', J Anal Chem+, 2007, 62, 51-57.

52. P Chambers, M O’Doherty, M Chalanqui, H O. McCarthy, N Dunne Krakow, Poland Sept 2015.

53. S. Bose and S. Tarafder, Acta Biomater, 2012, 8, 1401-1421.

54. M. Bohner, L. Galea and N. Doebelin, J Eur Ceram Soc, 2012, 32, 2663-2671.

55. K. H. Muller, M. Motskin, A. J. Philpott, A. F. Routh, C. M. Shanahan, M. J. Duer and J. N. Skepper, Biomaterials, 2014, 35, 1074-1088.

56. T. T. Morgan, T. M. Goff and J. H. Adair, Nanoscale, 2011, 3, 2044-2053.

57. A. Tabakovic, M. Kester and J. H. Adair, Wires Nanomed Nanobi, 2012, 4, 96-112.

58. T. Gonzalez-Fernandez, E. G. Tierney, G. M. Cunniffe, F. J. O'Brien and D. J. Kelly, Tissue Eng Part A, 2016, 22, 776-787.

59. S. V. Dorozhkin, Materials, 2013, 6, 3840-3942.

60. M. B. Evangelista, S. X. Hsiong, R. Fernandes, P. Sampaio, H. J. Kong, C. C. Barrias, R. Salema, M. A. Barbosa, D. J. Mooney and P. L. Granja, Biomaterials, 2007, 28, 3644-3655.

61. M. Grellier, P. L. Granja, J. C. Fricain, S. J. Bidarra, M. Renard, R. Bareille, C. Bourget, J. Amedee and M. A. Barbosa, Biomaterials, 2009, 30, 3271-3278.

62. S. J. Bidarra, C. C. Barrias, M. A. Barbosa, R. Soares and P. L. Granja, Biomacromolecules, 2010, 11, 1956-1964.

63. L. B. Priddy, O. Chaudhuri, H. Y. Stevens, L. Krishnan, B. A. Uhrig, N. J. Willett and R. E. Guldberg, Acta Biomaterialia, 2014, 10, 4390-4399.

64. M. F. Termaat, F. C. Den Boer, F. C. Bakker, P. Patka and H. J. T. M. Haarman, Journal of Bone and Joint Surgery-American Volume, 2005, 87a, 1367-1378.

65. D. Chen, M. Zhao and G. R. Mundy, Growth Factors, 2004, 22, 233-241.

66. R. Vaidya, R. Weir, A. Sethi, S. Meisterling, W. Hakeos and C. D. Wybo, J Bone Joint Surg Br, 2007, 89b, 342-345.

67. R. Vaidya, J. Carp, A. Sethi, S. Bartol, J. Craig and C. M. Les, European Spine Journal, 2007, 16, 1257-1265.

68. R. J. Mannion, A. M. Nowitzke and M. J. Wood, Spine J, 2011, 11, 527-533.

69. J. Y. Rho, L. Kuhn-Spearing and P. Zioupos, Med Eng Phys, 1998, 20, 92-102.

70. H. C. Anderson, R. Garimella and S. E. Tague, Front Biosci, 2005, 10, 822-837. 
Figure Legends

Fig.1: (A) Schematic representation of RALA-TCP (RTCP) nanoparticle preparation and delivery to MSC to obtain $R T C P$ delivered MSC (RTCP-MSC). (B) Schematic representation of $R T C P-M S C$ laden hydrogel preparation, and the hypothetical description of molecular events leading $R T C P$ induced bone formation.

Fig.2: Expression of growth factor genes and osteogenic marker genes in RALA conjugated TCP treated MSCs related to untreated controls at week 1 and 2 of in vitro culture. ${ }^{*} \mathrm{P}<0.05$ in upregulation and $+\mathrm{P}<0.05$ in downregulation compared to untreated control $(\mathrm{n}=3)$.

Fig.3: Long term viability, tissue formation and mineralization of RALA conjugated TCP treated MSCs (RTCP-MSC) and control MSCs (C-MSC) in alginate hydrogels in the absence of external growth factors. (A) is the live/dead confocal images of bare alginate hydrogels at 7 and 28 days of in vitro culture in neutral media. (B) is the histological images of bare alginate hydrogels cultured in neutral media for 28 days stained with H\&E sand alizarin red for detecting tissue formation and mineralization respectively. (C) is the biochemical quantification of calcium content in the bare alginate hydrogels incubated in cell neutral media $(\mathrm{CNM})$ for 28 days $(\mathrm{n}=4, * \mathrm{P}<0.05)$. Histology scale bar low magnification $500 \mu \mathrm{m}$, high magnification $100 \mu \mathrm{m}$.

Fig.4: Viability and proliferation of $R T C P-M S C$ in alginate hydrogels. Representative live/dead images of RTCP-MSC-hydrogels and C-MSC-hydrogels at 1 week in (A) chondrogenic and (B) osteogenic media respectively. DNA amount in the hydrogels at 3 weeks in chondrogenic and osteogenic growth conditions are shown as $(\mathrm{C})$ and (D) respectively. $* \mathrm{P}<0.05$ compared to $\mathrm{C}$ MSC-construct $(\mathrm{n}=5)$.

Fig.5: Effect of RALA conjugated TCP treated MSCs (RTCP-MSC) and control MSCs (CMSC) laden hydrogels in chondrogenesis, osteogenesis and mineralization in osteogenic and chondrogenic culture conditions. (A and B) are the histological images of the tissue engineered 
hydrogels incubated in chondrogenic media for 3 weeks stained with aldehyde fuchsin/alcian blue $(\mathrm{AF} / \mathrm{AB})$, picrosirius red and alizarin red for detecting the presence and distribution of sGAGs, collagen and mineralization respectively. Black arrow in (A) shows mineral deposits in the hydrogels even in chondrogenic conditions. Scale bar low magnification $500 \mu \mathrm{m}$, high magnification $100 \mu \mathrm{m}$.

Fig.6: Bone formation in the hydrogels 8 weeks after in vivo implantation. (A) Representative gross morphology $(\mathrm{a}, \mathrm{c})$ and $\mu \mathrm{CT}$ images $(\mathrm{b}, \mathrm{d})$ of control MSCs (C-MSC) and RALA conjugated TCP treated MSCs (RTCP-MSC) laden alginate hydrogels. (B) Representative images of C-MSC and RTCP-MSC laden alginate hydrogel sections stained with haematoxylin/eosin and alizarin red respectively. (C) Representative gross morphology (e, g) and $\mu \mathrm{CT}$ images (f, g) of C-MSC and RTCP-MSC laden growth factor (GF)-loaded alginate hydrogels. (D) Representative histological images of C-MSC and RTCP-MSC laden GFloaded alginate hydrogel sections stained with haematoxylins/eosin and alizarin red respectively. (E) Biochemical quantification of collagen content in the hydrogels $(n=3)$. (F) Bone tissue volume quantified from the histological images of the hydrogels $(\mathrm{n}=5, * \mathrm{P}<0.05)$. (G) Mineral volume quantified using $\mu \mathrm{CT}$ imaging $(\mathrm{n}=8, * \mathrm{P}<0.05)$. Histology scale bar low magnification $500 \mu \mathrm{m}$, high magnification $100 \mu \mathrm{m}$.

Fig.7: Bone formation in tissue engineered hydrogels first primed in vitro in chondrogenic media for 6 weeks before in vivo implantation for 8 weeks. (A) Representative images of control MSCs (C-MSC) and RALA conjugated TCP treated MSCs (RTCP-MSC) laden alginate hydrogel sections stained with aldehyde fuchsin/alcian blue (AF/AB) for sGAGs, picrosirius red for collagen and alizarin red for mineralization respectively after 6 weeks of in vitro chondrogenic priming. (B) Biochemical quantification of collagen $(n=5)$ and calcium $(n$ $=5$ ) content of engineered tissues after 6 weeks of in vitro priming. (C) Representative gross morphology (a and c), $\mu \mathrm{CT}$ image (b and d) of $C-M S C$ and $R T C P-M S C$ laden alginate 
hydrogels, as well as sections stained with haematoxylin/eosin and alizarin red respectively 8 weeks after in vivo implantation. (D) Biochemical quantification of collagen content $(\mathrm{n}=3)$ and $\mu \mathrm{CT}$ quantification of mineral volume $(\mathrm{n}=8)$ in the hydrogels 8 weeks after in vivo implantation. Histology scale bar low magnification $500 \mu \mathrm{m}$, high magnification $100 \mu \mathrm{m}$.

Fig.1

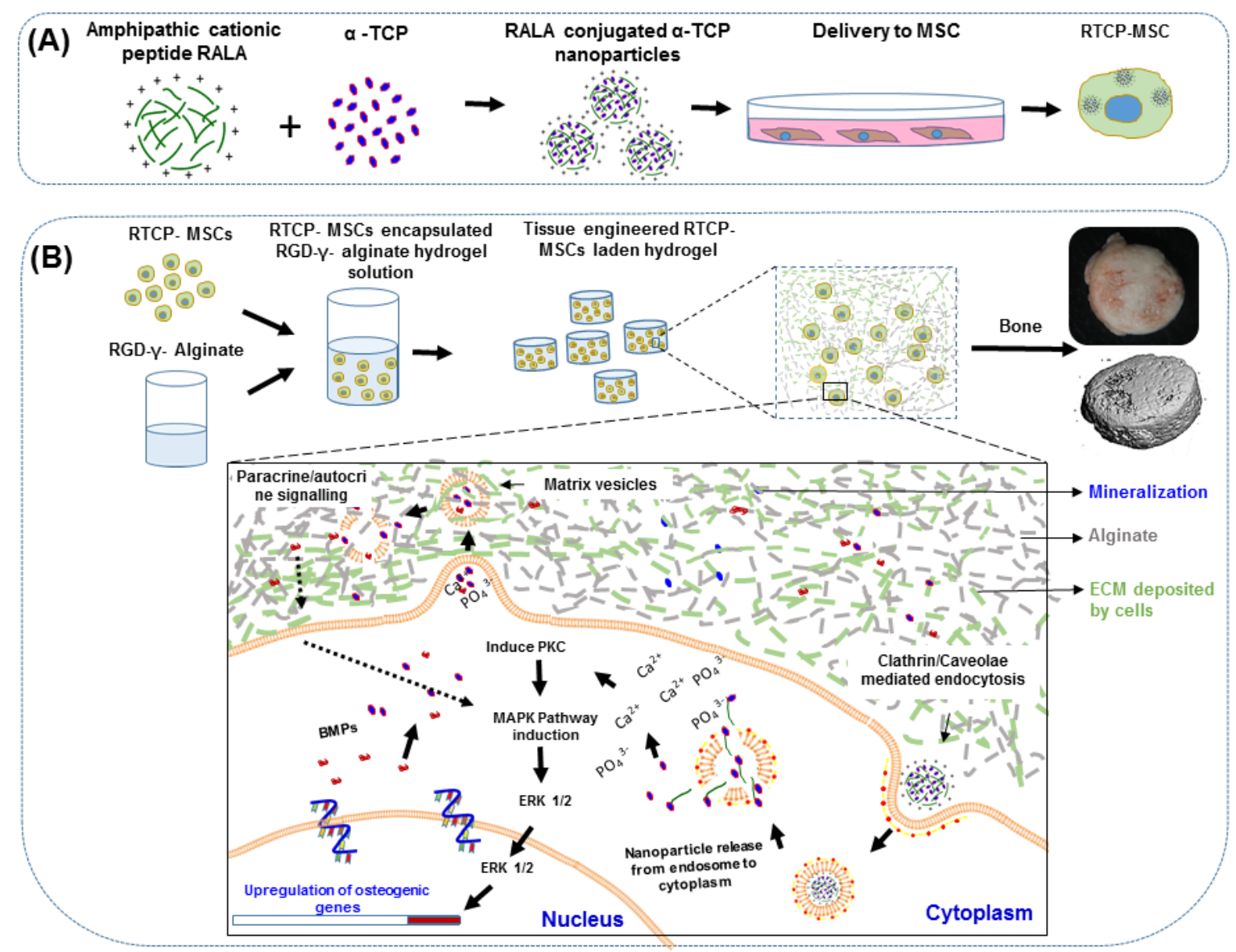


Fig. 2
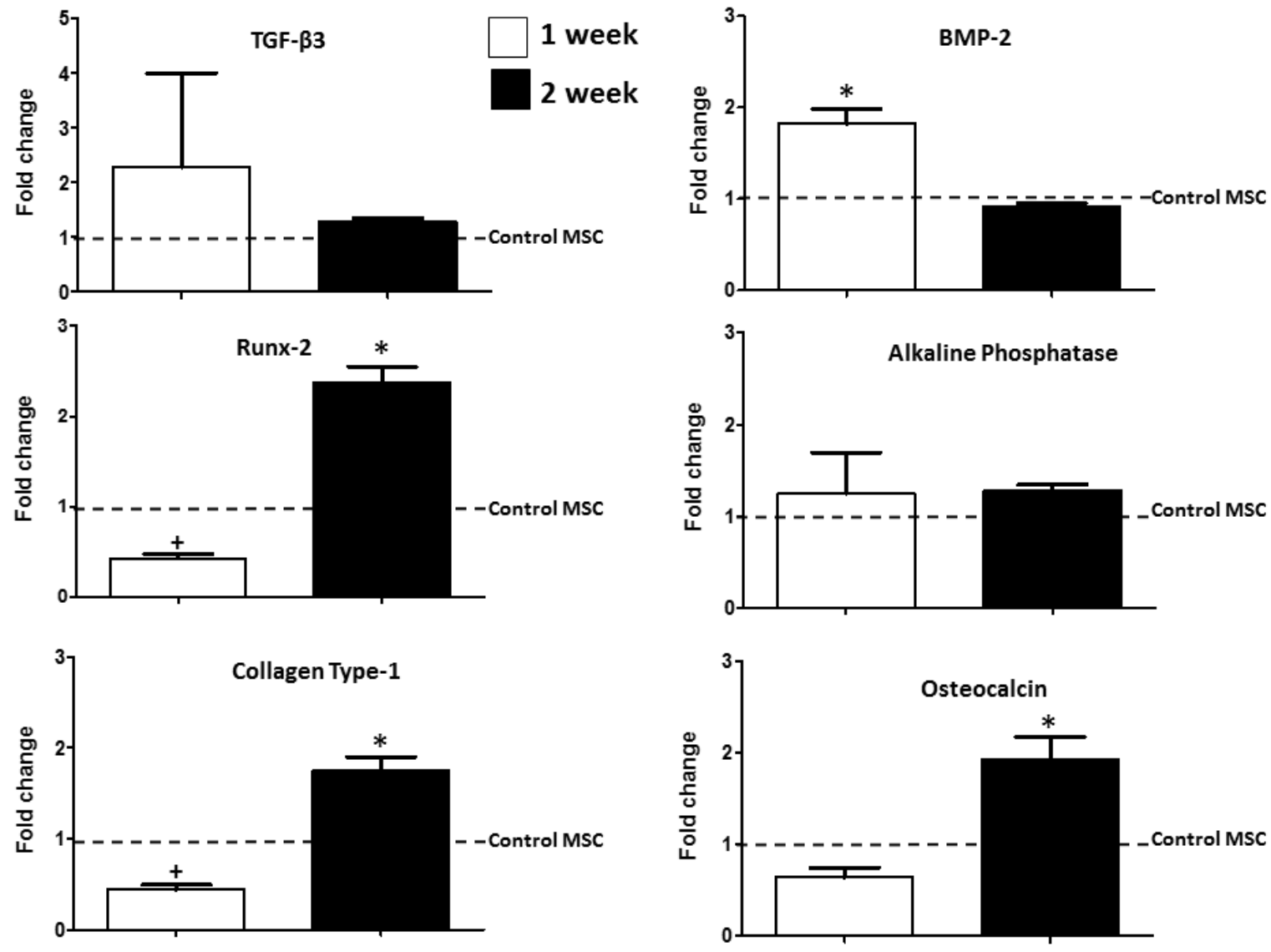
Fig. 3

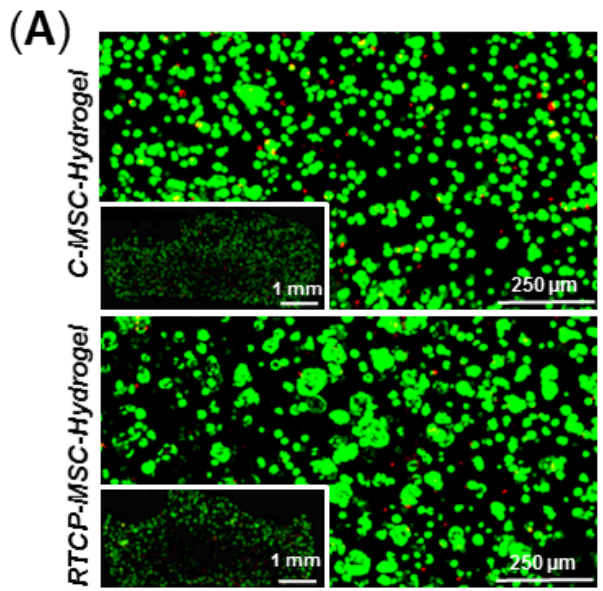

(C)

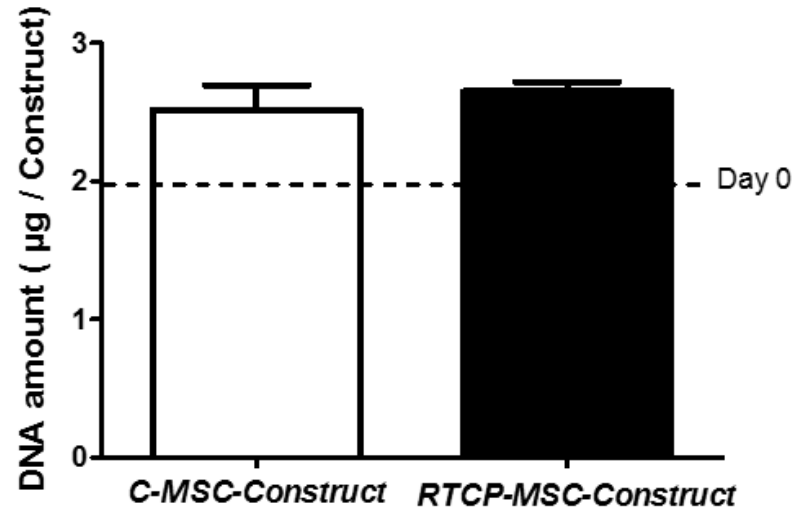

(B)

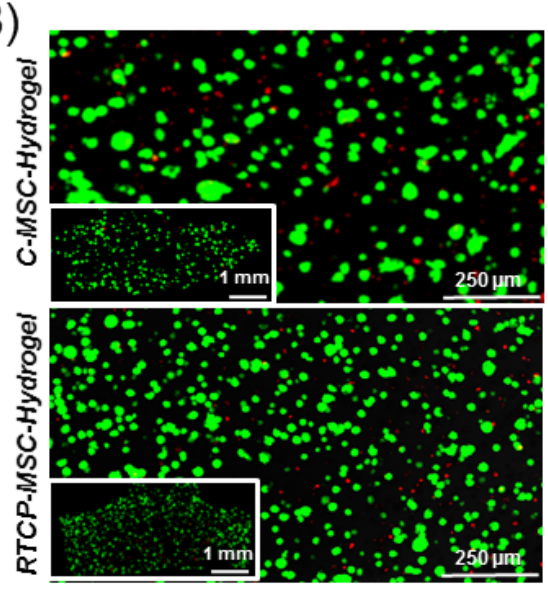

(D)

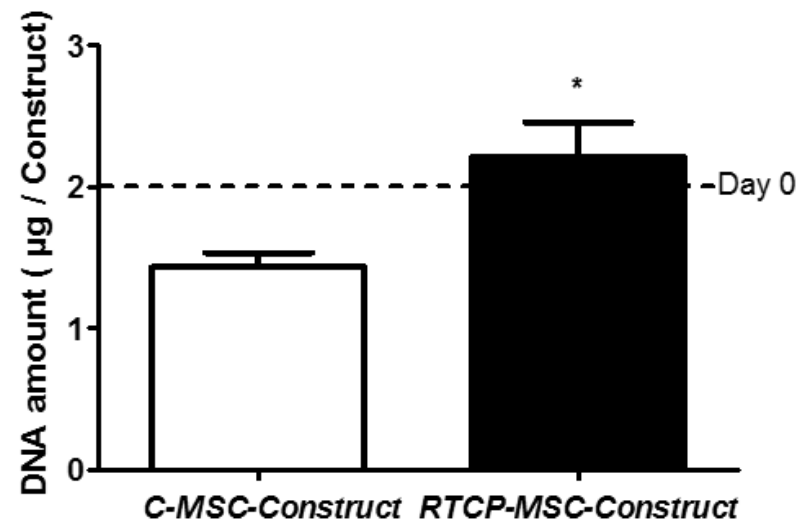

Fig.4

A

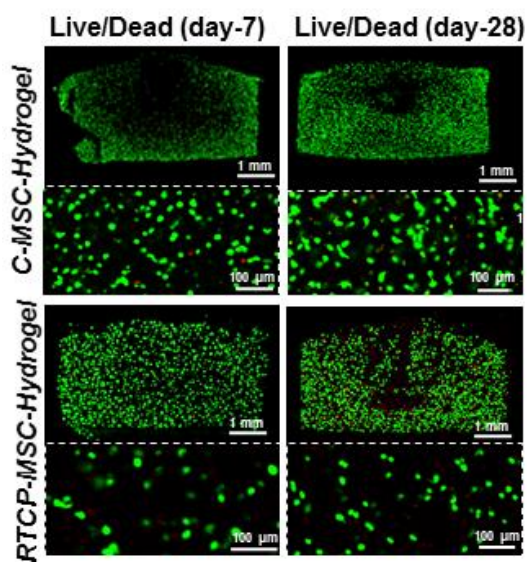

B

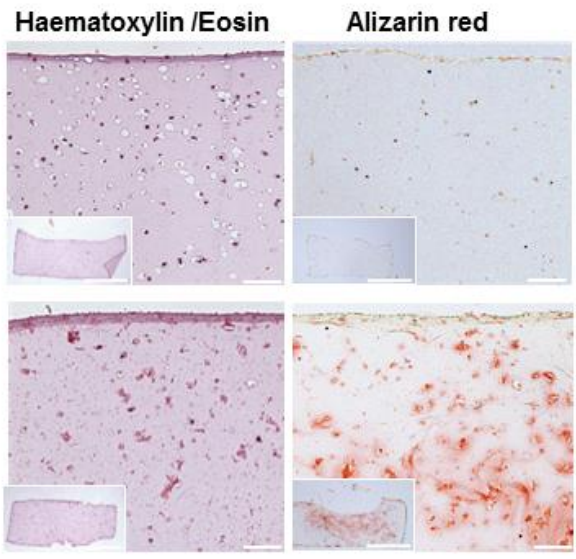

C

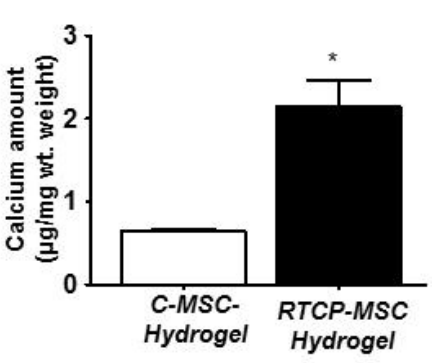


Fig.5
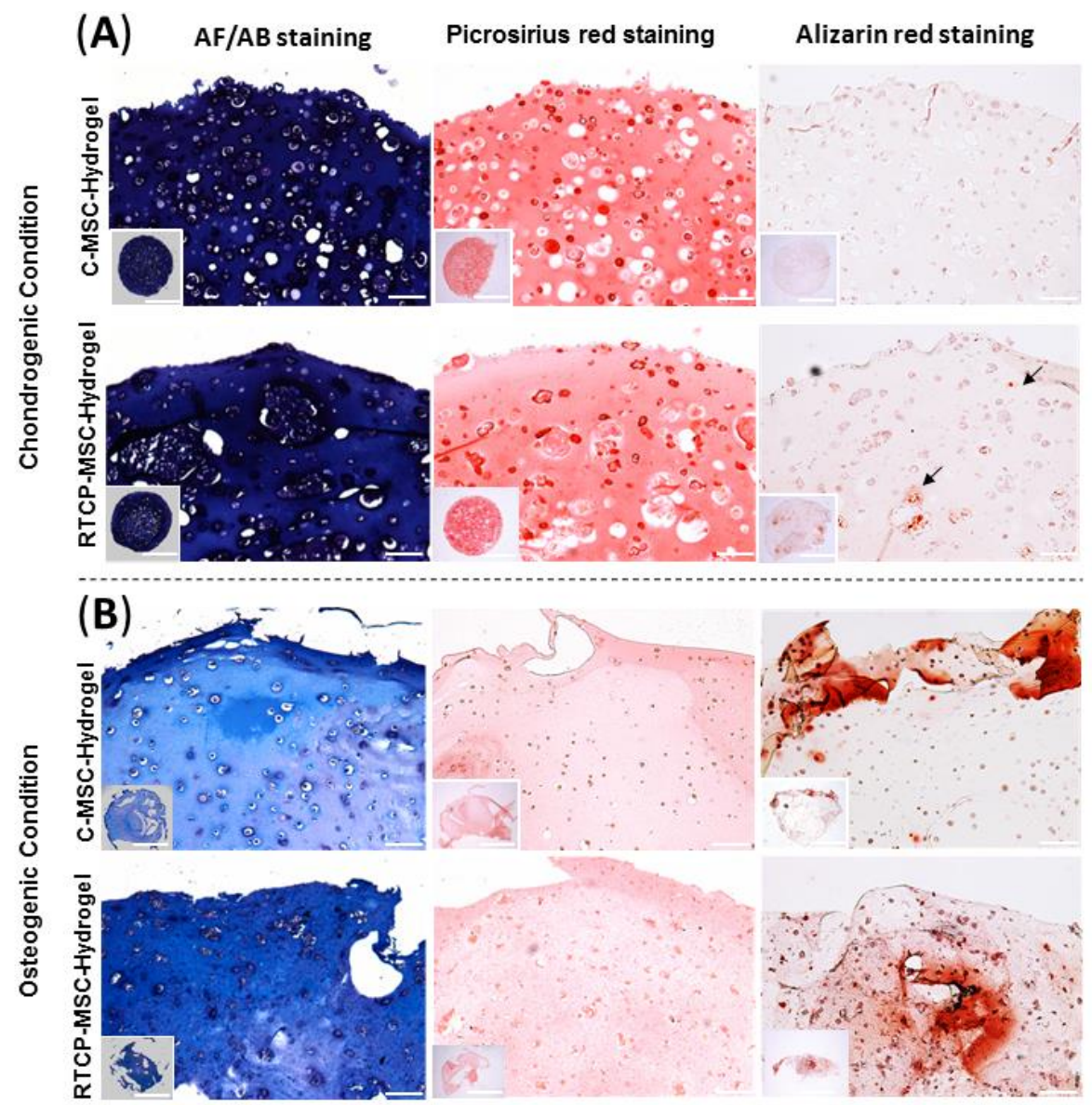
Fig. 6

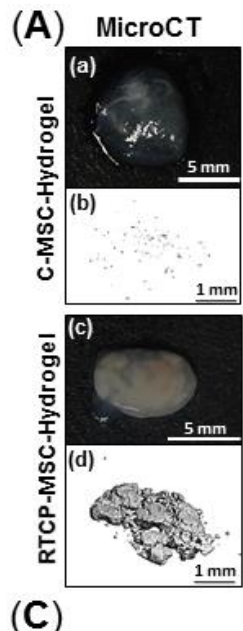

(B) Hematoxylin/Eosin

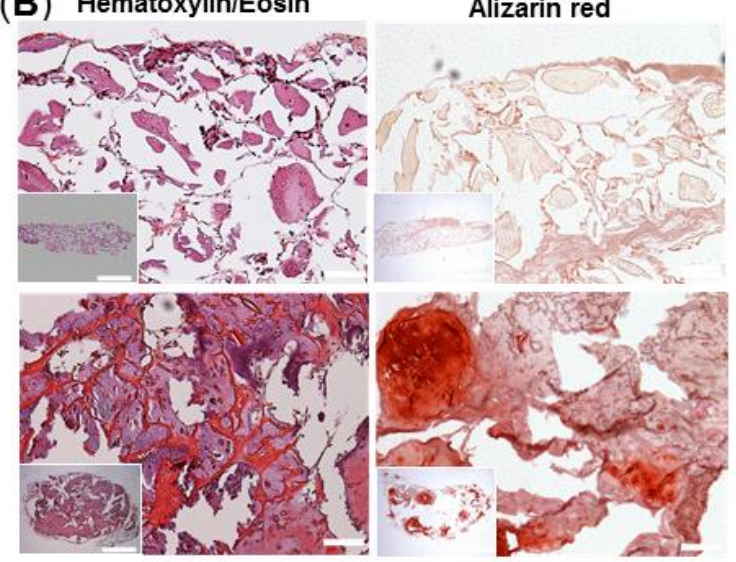

(C)

(D)
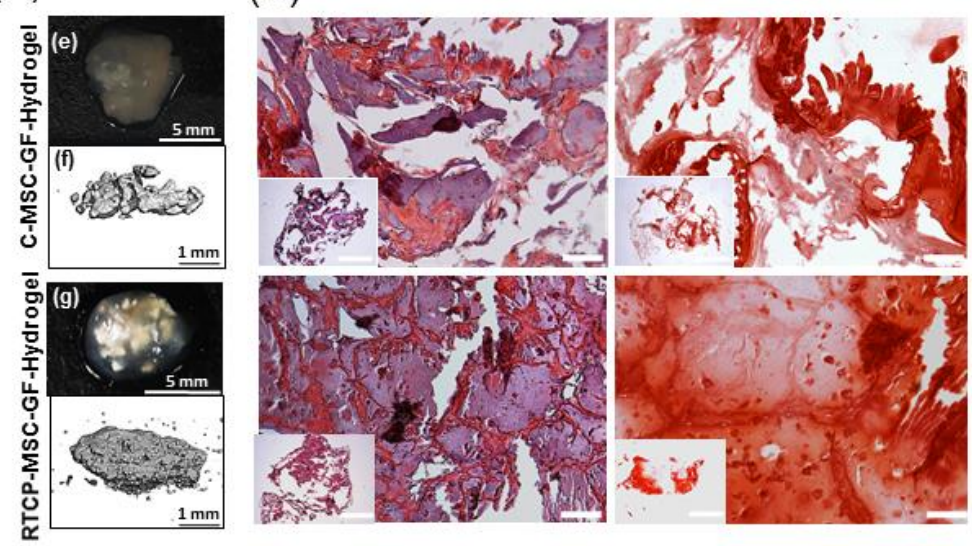

(E)

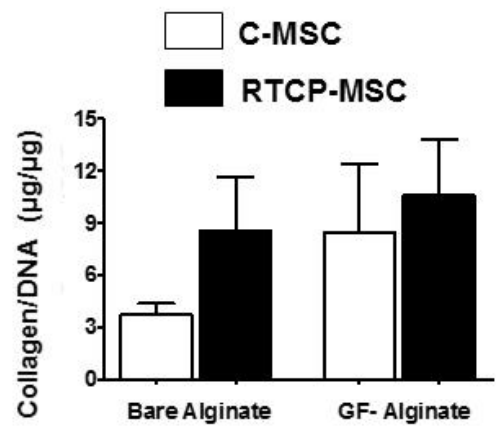

(F)

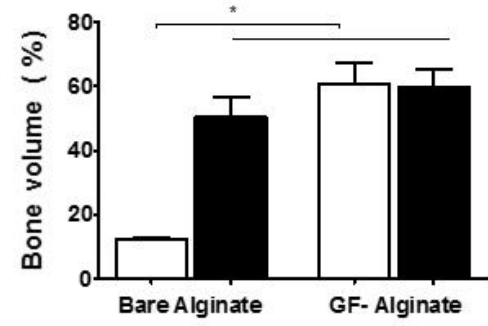

(G)

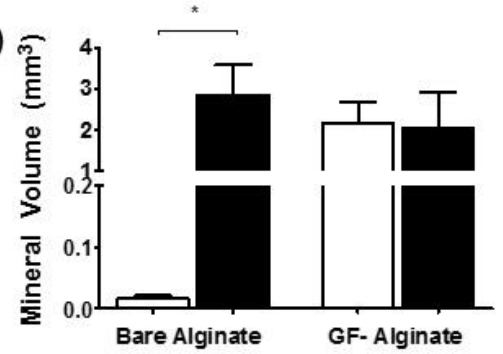


Fig.7
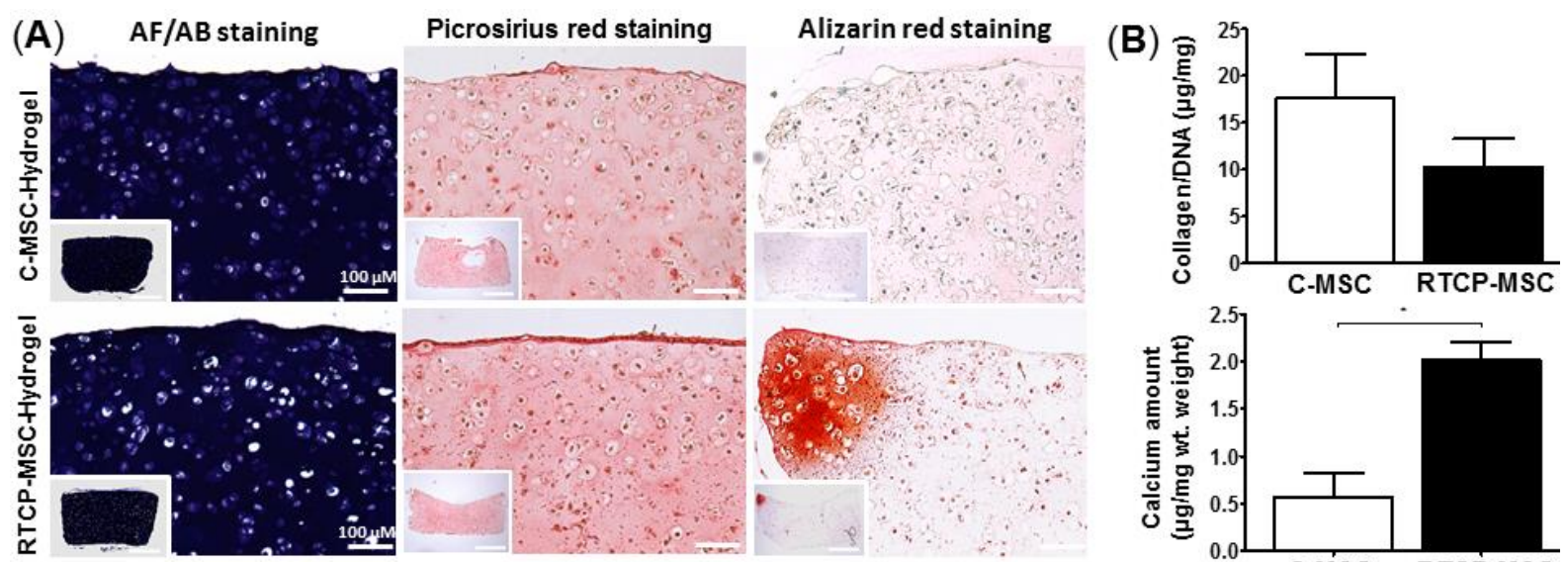

(C)

HE staining
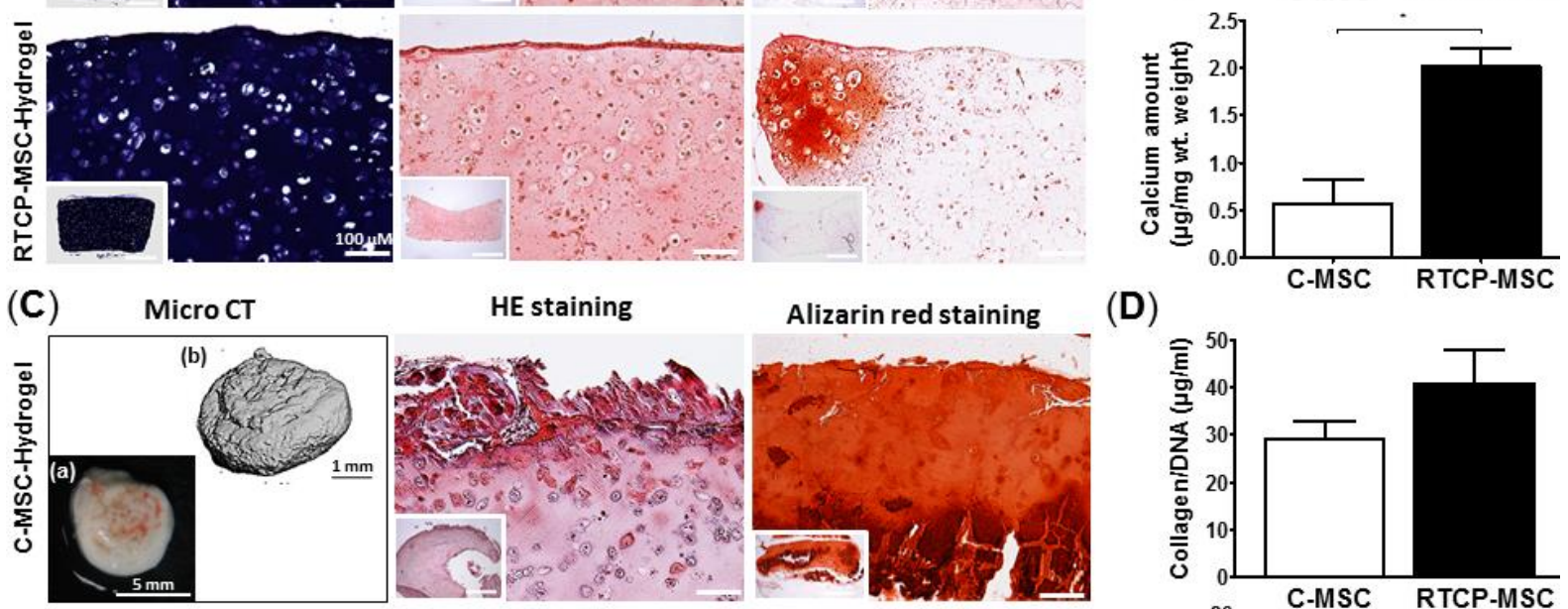

Alizarin red staining

(D)
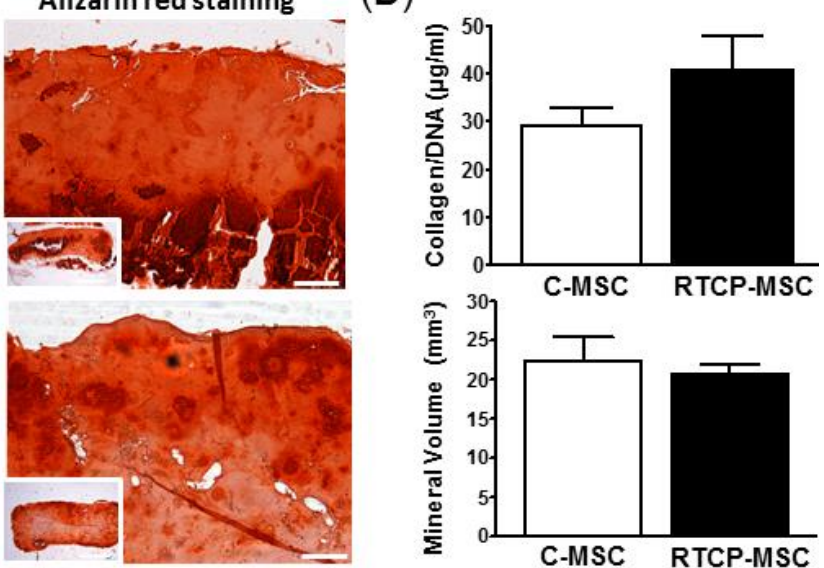
Table-1: Composition of tissue engineered hydrogels

\begin{tabular}{ccccc}
\hline Constructs & RGD-alginate & Growth Factor & Control-MSC & RTCP-MSC \\
\hline- & - & - & $\sqrt{ }$ & $\sqrt{ }$ \\
\hline$C-M S C$-hydrogel & $\sqrt{ }$ & - & $\sqrt{ }$ & - \\
\hline$R T C P-M S C$ - hydrogel & $\sqrt{ }$ & - & $\sqrt{ }$ \\
\hline$C-M S C-G F-$ hydrogel & $\sqrt{ }$ & $\sqrt{ }$ & \\
\hline$R T C P-M S C-G F-$ hydrogel & $\sqrt{ }$ & $\sqrt{ }$ & - & $\sqrt{ }$ \\
\hline
\end{tabular}


Table 2: Experimental groups, conditions and duration of each study

\begin{tabular}{|c|c|c|c|c|c|c|}
\hline & $\begin{array}{l}\text { Stud } \\
\text { ies } \\
\end{array}$ & $\begin{array}{l}\text { Experimental } \\
\text { groups }\end{array}$ & $\begin{array}{l}\text { Sample/Constru } \\
\text { ct types }\end{array}$ & $\begin{array}{l}\text { Cell neutral } \\
\text { media }\end{array}$ & $\begin{array}{l}\text { Osteogenic } \\
\text { media }\end{array}$ & $\begin{array}{l}\text { Chondrogeni } \\
\text { c media }\end{array}$ \\
\hline \multirow{7}{*}{ 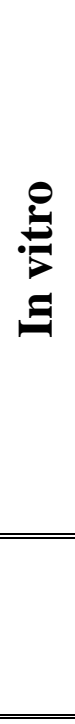 } & \multirow{2}{*}{$\begin{array}{l}\text { Study } \\
-1\end{array}$} & Group-1 & C-MSC-monolayer & 1 and 2 weeks & & \\
\hline & & Group-2 & $\begin{array}{l}R T C P-M S C- \\
\text { monolayer }\end{array}$ & 1 and 2 weeks & & \\
\hline & \multirow{2}{*}{$\begin{array}{c}\text { Study } \\
-2\end{array}$} & Group-3 & C-MSC-hydrogel & & 4 weeks & \\
\hline & & Group-4 & $\begin{array}{l}\text { RTCP-MSC- } \\
\text { hydrogel }\end{array}$ & & 4 weeks & \\
\hline & \multirow{3}{*}{$\begin{array}{l}\text { Study } \\
-3\end{array}$} & Group-5 & C-MSC-hydrogel & & & 3 weeks \\
\hline & & Group-6 & $\begin{array}{c}\text { RTCP-MSC- } \\
\text { hydrogel }\end{array}$ & & & 3 weeks \\
\hline & & & Construct types & $\begin{array}{c}\text { In vitro } \\
\text { chondrogeni } \\
\text { c priming } \\
\text { period } \\
\end{array}$ & $\begin{array}{l}\text { In vivo } \\
\text { period }\end{array}$ & $\begin{array}{l}\text { Number of } \\
\text { hydrogels }\end{array}$ \\
\hline \multirow{6}{*}{$\stackrel{0}{2}$} & \multirow{4}{*}{$\begin{array}{l}\text { Study } \\
-1\end{array}$} & Group-1 & C-MSC-hydrogel & None & 8 weeks & 8 \\
\hline & & Group-2 & $\begin{array}{l}\text { RTCP-MSC- } \\
\text { hydrogel }\end{array}$ & None & 8 weeks & 8 \\
\hline & & Group-3 & $\begin{array}{l}\text { C-MSC-GF- } \\
\text { hydrogel }\end{array}$ & None & 8 weeks & 8 \\
\hline & & Group-4 & $\begin{array}{c}\text { RTCP-MSC-GF- } \\
\text { hydrogel }\end{array}$ & None & 8 weeks & 8 \\
\hline & \multirow{2}{*}{$\begin{array}{l}\text { Study } \\
-2\end{array}$} & Group-5 & C-MSC-hydrogel & 6 weeks & 8 weeks & 8 \\
\hline & & Group-6 & $\begin{array}{l}\text { RTCP-MSC- } \\
\text { hydrogel }\end{array}$ & 6 weeks & 8 weeks & 8 \\
\hline
\end{tabular}


Table 3. Primer sequences used for real-time PCR

\begin{tabular}{c|cc}
\hline Gene & Forward primer & Reverse primer \\
\hline COL1A1 & TAGACATGTTCAGCTTTGTG & GTGGGATGTCTTCTTCTTG \\
\hline RUNX2 & CCAACAGAGGCATTTAAGG & CCAAAAGAAGTTTTGCTGAC \\
\hline BMP-2 & ATGTGGAGGCTCTTTCAATG & CATGGTCGACCTTTAGGAG \\
\hline TGFß3 & GAGTACTATGCCAAGGAAATC & TTGAAGCGGAAAATCTTGG \\
\hline ALPL & TTTCACTCTTCTTAGTGCTG & CGTTACGGAATGAGGAAAC \\
\hline BGLAP & CAGGAGGGAGGTGTGTGAG & TGCGAGGTCTAGGCTATGC \\
\hline GAPDH & TTTAACTCTGGCAAAGTGG & GAACATGTAGACCATGTAGTG \\
\hline
\end{tabular}

